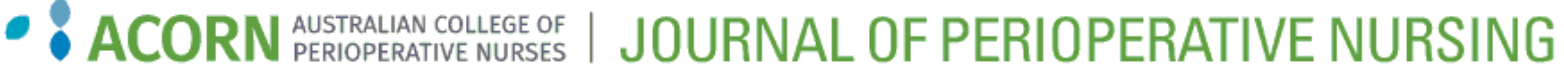

\title{
The imperative to build research capacity and promote evidence- based practice in Australian perioperative nurses
}

Follow this and additional works at: https://www.journal.acorn.org.au/jpn

Part of the Health Services Administration Commons, Health Services Research Commons, Perioperative, Operating Room and Surgical Nursing Commons, and the Surgery Commons

(c) (i)

This work is licensed under a Creative Commons Attribution 4.0 License.

\section{Recommended Citation}

Duff, Jed (2020) "The imperative to build research capacity and promote evidence-based practice in Australian perioperative nurses," Journal of Perioperative Nursing: Vol. 33 : Iss. 2 , Article 3.

Available at: https://doi.org/10.26550/2209-1092.1086

https://www.journal.acorn.org.au/jpn/vol33/iss2/3

This Editorial is brought to you for free and open access by Journal of Perioperative Nursing. It has been accepted for inclusion in Journal of Perioperative Nursing by an authorized editor of Journal of Perioperative Nursing. 


\section{ACORN}

The Australian College of Perioperative Nurses (ACORN) is a registered Australian company and health promotion charity. ACORN is Australia's peak body for perioperative nursing.

Mission: Our work is to advance safe, quality perioperative nursing care for Australians.

Vision: When our work is done Australians receive safe, quality perioperative nursing care.

Values: As we work, we are committed to collaboration, excellence,

communication and innovation.

\section{ACORN Board of Directors}

Patricia Flood

President

Elyse Coffey

Director

Sophie Ehrlich

Director

Karen Hay

Director

Jessica Pougnault

Director

Donna Stevens

Director

Garry Stratton

Director

\section{The imperative} to build research

Associate Professor Jed Duff PhD, RN

Journal Editor

\section{capacity and promote evidence- based practice in Australian perioperative nurses}

Evidence-based practice is considered the gold standard of care, and as such it is now an expectation of our patients, regulatory agencies and health care funders. Unfortunately, much of what we do in perioperative nursing continues to be based on tradition and history rather than robust clinical evidence. Even when evidence is available to use, it is often not fully applied in practice. If we want to maintain our standing as a leading nursing specialty, then we need to address this issue by engaging with research and growing our evidence base. To do this, we need to conduct and disseminate rigorous primary research, clinically relevant systematic reviews and evidence-based practice projects.

As it stands, there is a growing divide, in Australia, between nursing specialties that are active in research and those that are not research active. Emergency Department (ED) and Intensive Care Unit (ICU) nursing are similar high-acuity specialties with comparable numbers of nurses nationally and, as seen in Figure 1, research publications related to ED and ICU have dramatically increased over the past 20 years while publications related to perioperative nursing remain unchanged. Four to five times more evidence is currently being generated each year

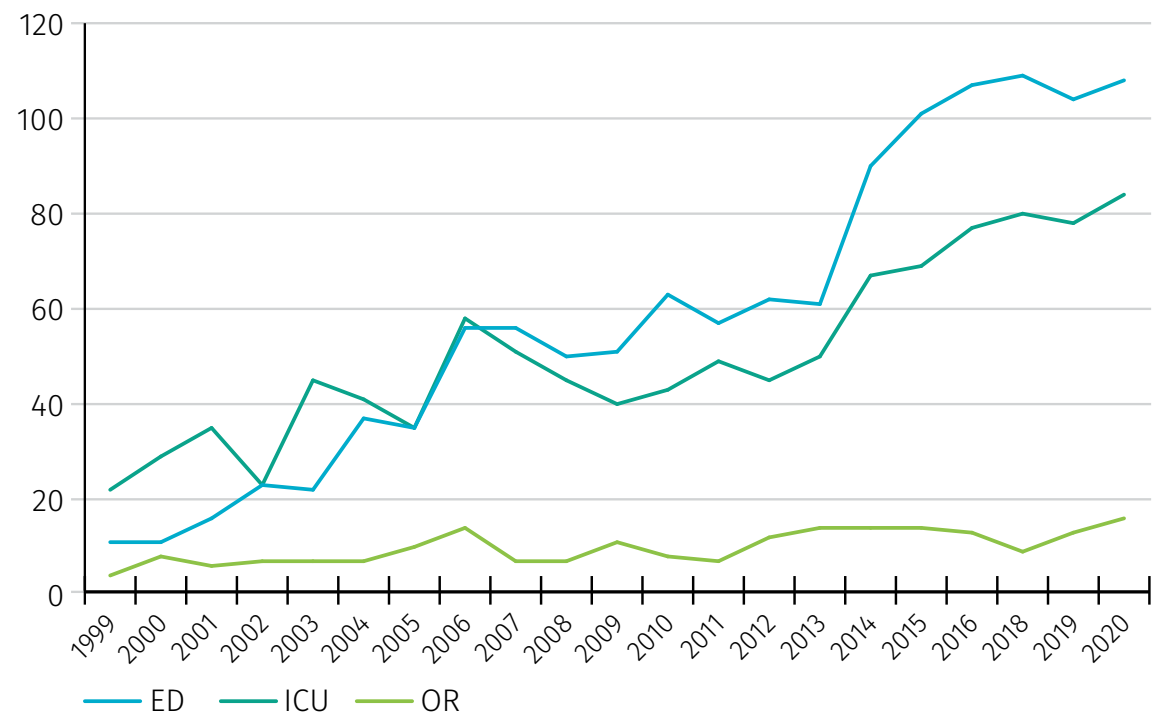

Figure 1: Annual publications per year related to Emergency Department (ED), Intensive Care Unit (ICU) and perioperative nursing 
for ED and ICU nursing compared to perioperative nursing and this looks set to continue without immediate action.

We are all aware that the demand for surgery is increasing at a dramatic rate in Australia. This growth, coupled with the ageing nursing workforce, is placing considerable pressure on service delivery. Perioperative nursing runs the risk of being supplanted by non-nursing para-professionals if we cannot demonstrate through research what we do and why it is beneficial. Globally, perioperative nursing is under pressure from surgical technicians and physicians' assistants, and it is not inconceivable that this may happen in Australia too. It is clear that, as a specialty, we need to build research capacity to strengthen our evidence base.

The ACORN Research Committee, chaired by Prof. Brigid Gillespie, is actively working to build research capacity and promote evidence-based practice in Australian perioperative nurses. Here I would like to highlight three of its initiatives for this year. First, the committee has completed a survey to identify the top research priorities for perioperative nursing; this will be published in an upcoming issue. Second, the research webinar series is continuing, and this year includes a three-minute thesis competition for higher degree research students. Third, the annual grant which supports members to undertake perioperative nursing research will be open for applications later in the year.

This journal, Journal of Perioperative Nursing (JPN), also helps promote evidence-based practice in our specialty by providing a reputable place for our researchers, scholars and students to publish and by sharing their work online with nurses across the world. Since the JPN online open-access repository launched

Is your graduate nurse suffering from transition shock?

Erin Wakefield

The patient, case, individual and environmental factors that impact on the surgical count process: An integrative review

Victoria Warwick, Brigid Gillespie, Anne McMurray and Karen Clark-Burg

Cloth hats: (W)Hat's the issue

Elizabeth McKenna

Pressure injury risk assessment and prevention strategies in operating room patients - findings from a study tour of novel practices in American hospitals

Lauren Goudas and Steven Bruni

Clinical handover of immediate post-operative patients: A literature review Samantha Clarke, Karen Clark-Burg and Elaine Pavlos

Refining guidelines for the care of paediatric perioperative patients in a rural health care facility

Michelle Hibberson

Handover between anaesthetists and post-anaesthetic care unit nursing staff using ISBAR principles: A quality improvement study

Patricia Kitney, Raymond Tam, Paul Bennett, Dianne Buttigieg, David Bramley and Wei Wang

Technology stress in perioperative nursing: An ongoing concern

Judith Smith and Debra Palesy

Figure 2: Top eight JPN papers based on the average number of full-text downloads per day since publication

two years ago, there have been over 17500 full-text downloads from readers across the globe. Figure 2 is a list of the journal's top eight articles based on the average number of full-text downloads per day since release. I would like to congratulate all of the authors and thank them for publishing in JPN.

I would particularly like to congratulate, Erin Wakefield, the winner of the inaugural JPN Best Paper award for her work titled 'Is your graduate nurse suffering from transition shock?' Her paper - downloaded almost 2500 times to date - describes signs, symptoms, and mitigation strategies and provides readers with the ability to recognise transition shock so that they can better support perioperative nursing graduates. Erin's paper is an example of the nursing research and scholarship we need to encourage in our specialty. Please feel free to contact me if you would also like to contribute to the perioperative nursing evidence base by publishing your work. 